\title{
Comparison of design for composite columns in steel and concrete according to Eurocode 4 and Chinese design codes
}

\author{
Q. Zhang ${ }^{a *}$, M. Schäfer ${ }^{\mathrm{a}}$ \\ ${ }^{\text {a }}$ Faculty of Science, Technology and Communication, University of Luxembourg, Luxembourg \\ * corresponding author, e-mail address: qingjie.zhang@uni.lu
}

\begin{abstract}
This paper compares the design of composite columns in steel and concrete based on EN1994-1-1 and Chinese JGJ138-2016. First, the application ranges of the codes are pointed out. Both codes contain the design of fully encased composite sections and concrete filled rectangular and circular tubes. However, there are different limitations on crosssection sizes, material strength classes, and others. JGJ138 has three separate chapters for the designs related to the three different types of columns. Eurocode 4 gives three different design methods: one general method based on nonlinear calculation, and two simplified methods based on European buckling curves or N-M iteration curves. For the materials, mechanical properties, such as design strength values, are compared based on the same material grade. For axial compression resistance and eccentrically compressive resistance, the two simplified methods from Eurocode 4 are compared with the design method according to JGJ138-2016 through theoretical and parameter studies. The influences of related parameters such as long-term effects, the buckling curves, and N-M iteration curves are also compared. For shear design, JGJ138-2016 considers mainly transverse shear resistances, while Eurocode 4 further considers shear connection and load introduction. The design transverse shear resistance is compared through theory.
\end{abstract}

Keywords: Composite column; Eurocode 4; JGJ138-2016.

\section{Introduction}

As the result of rapid economic growth, a booming building industry is ongoing in China. Around half of the world's new constructions are built there each year recently [1], among which, composite structures become more important. In parallel, there are new developments for Chinese design codes. Thus, it is interesting to compare the newly published Chinese "Code for design of composite structures" JGJ138-2016 [2] (JGJ138 for short) with globally used Eurocode 4: part 11 (EN1994-1-1) [3] (EC4 for short), the most technically advanced standard for the design of composite structures. Funded by the European Commission, in context of Erasmus + strategic partnership project "AVEC BNT," a detailed comparison of these two codes is now proceeding. This paper is a summary of parts of the results. For JGJ138-2016, "JGJ" is an abbreviation of its name in Chinese Pinyin "Jian Gong Jian" which means "standards for construction engineering." Similarly, the abbreviation "GB" for some Chinese codes [4] is from "Guo Biao" which means "national standard". Both JGJ138-2016 and EN1994-1-1 are based on probabilistic safety concept, and limit states design method, which allows the comparison of both codes.

\section{Application scope of the codes}

Eurocode 4 represents three different design methods: The simplified method, based on the European buckling curves for axial compression. In addition, a simplified method based on the $2^{\text {nd }}$ order calculation for action effects considering imperfections and N-M interaction for the determination of resistances, for centric and eccentric loadings. As well as the general method with non-linear FE-Analysis based on the stress-strain relationship of materials, considering geometrical imperfections and residual stresses. For each type of columns, JGJ138-2016 gives different equations for the calculation of column resistance under centric or 
eccentric loading. Most of the equations are adopted from the code for design of concrete structures GB50010 [4].

Eurocode 4 allows designs with normal strength concrete (C20/25 to C50/60), the steel contribution ratio should be between 0.2 and 0.9 . Chinese code moreover uses high strength concrete with cube strength class up to $\mathrm{C} 80$, also low strength reinforcements are allowed.
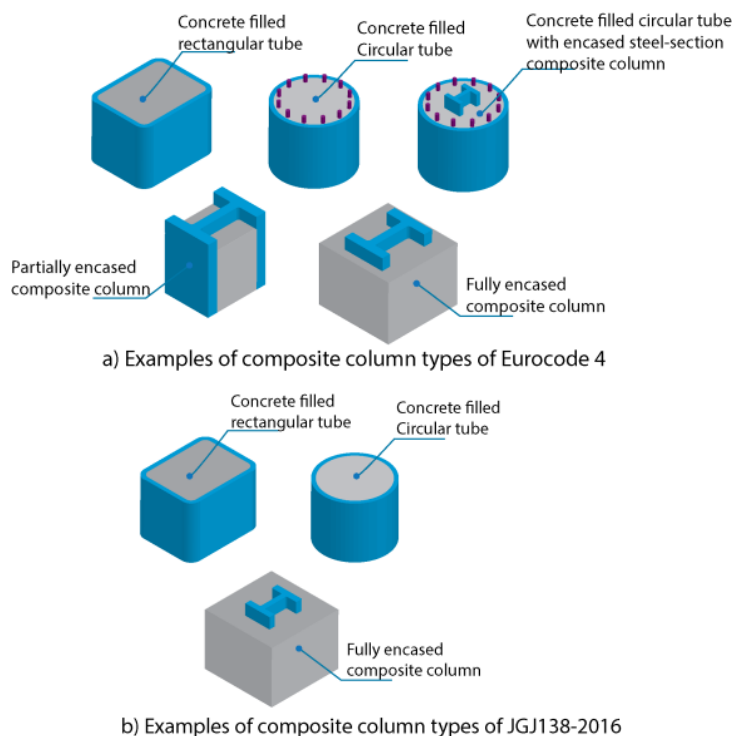

Fig. 1. Column types allowed by the simplified method in EC4 and JGJ138-2016

Table 1.Considered parameters, design possibilities in EC4 simplified method and JGJ138-2016

\begin{tabular}{|c|c|c|}
\hline Considerations & EC4 & JGJ138 \\
\hline \multicolumn{3}{|c|}{ Considered parameters } \\
\hline Imperfection on axial compression & $\bullet$ & $\bullet$ \\
\hline Imperfection on N-M interaction & $x$ & $\bullet$ \\
\hline $\begin{array}{l}\text { Influence of transverse shear on } \\
\text { steel strength }\end{array}$ & $\bullet$ & $x$ \\
\hline Second-order effects & $\bullet$ & $\circ$ \\
\hline Longitudinal shear, loads transfer & $\bullet$ & $x$ \\
\hline \multicolumn{3}{|c|}{ Design possibilities } \\
\hline Axial compression & $\bullet$ & $\bullet$ \\
\hline Eccentric compression & $\bullet$ & $\bullet$ \\
\hline Axial tension & $x$ & $\bullet$ \\
\hline Eccentric tension & $x$ & $\bullet$ \\
\hline Transverse shear & $\bullet$ & $\bullet$ \\
\hline Seismic design & $\times$ & $\bullet$ \\
\hline Non-regular cross-section types & $\bullet$ & $\times$ \\
\hline - Yes $\circ$ optional $\times$ No & & \\
\hline
\end{tabular}

rectangular and circular tubes, but with different limitations. Furthermore, Eurocode 4 also allows more section types, which are doubly symmetrical and connected, such as the partially encased composite sections, and combined steel tubes with encased steel sections (Fig. 1a), [5].The comparisons of general limitations are shown in Fig. 2. With the limitation of very thick concrete encasement out of steel section and big cross-section size, JGJ138 is suitable for mega columns, while EC4 also allows smaller sections. Comparison of considered parameters and design possibilities of simplified methods in EC4 and methods in JGJ138 are compared in Table 1. For the general nonlinear method of EC4, columns with unregularly, asymmetric or with unconnected multi-steel profiles crosssections are allowed.

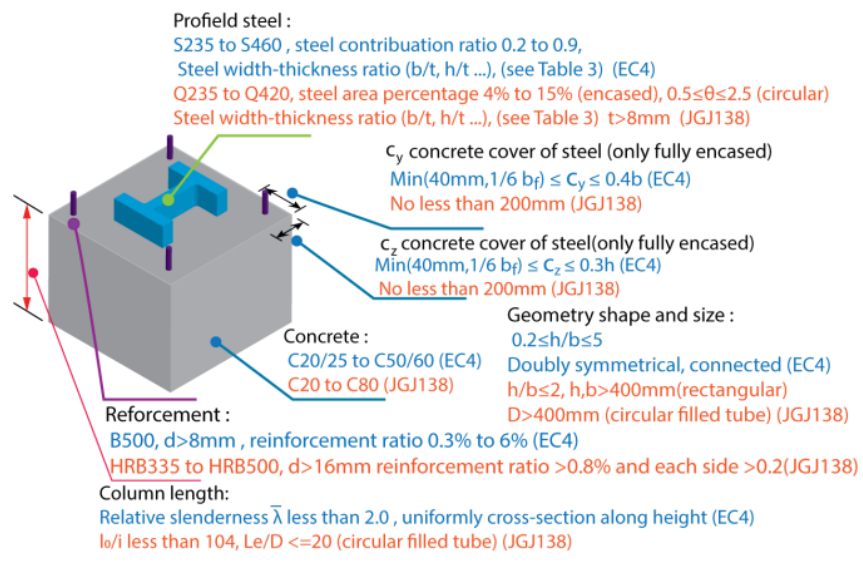

Fig. 2. Comparison of the limitations of the composite column design

\section{Comparison of material}

\subsection{Concrete}

EC4 (references to EN1992-1-1) gives two characters for the concrete strength class; the first value represents cylinder strength class

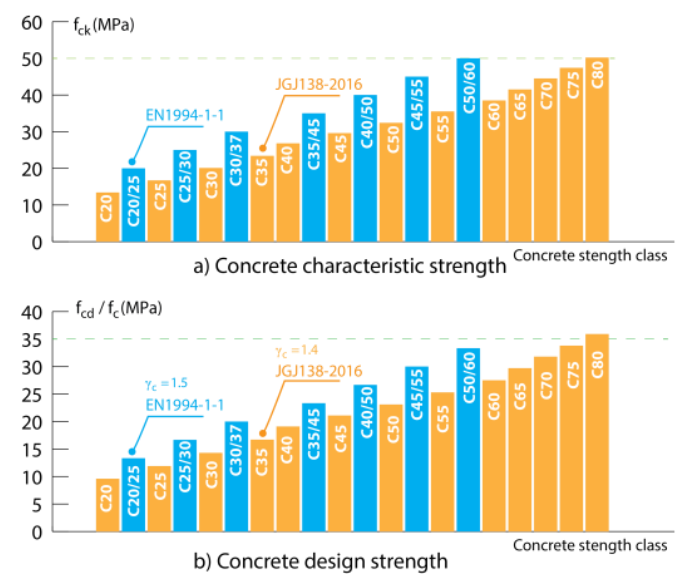

Fig. 3. Comparison of concrete strength 
and the other represents cube strength class. JGJ138 similar to GB50010 [4] uses only cube strength class.

In Chinese design codes, concrete characteristic compression strength $\left(\mathrm{f}_{\mathrm{ck}}\right)$ is based on concrete from the "real" structures, which considers time effects and other factors [1]. It is about $20 \%$ smaller than in EC4. For concrete design compression strength, EN1994-1-1 $\left(\mathrm{f}_{\mathrm{cd}}\right)$ applies material partial safety factor of 1.5 (or 1.2 for accidental combination). JGJ138-2010 $\left(\mathrm{f}_{\mathrm{c}}\right)$ uses 1.4. For concrete with same cube strength class, Eurocode 4 has around 14\% higher design strength, without considering the reduction factor $\alpha_{c c}$ of time effect by EN19921-1. The use of $a_{c c}$ also in EC4 is still suggested to be included in future version [6].

\subsection{Profiled steel and reinforcement}

Material properties for structural steel and reinforcement, based on EC4 and JGJ138 are listed in Table 2. There are a few important differences: JGJ138 allows using low strength reinforcement such as HRB335, HRB400, and for HRB500 different design strength vaule for tension and compression. EC4 can use higher strength structural steel of S450 and S460. The material safety factor for structural steel in JGJ138 is around 1.1, while EC4 suggests 1.0 for cross-section resistance and instability checking.

Table 2.Structural steel and reinforcement mechanic properties in Eurocode 4 and JGJ138-2016.

\begin{tabular}{|c|c|c|}
\hline Properties & EN1994-1-1 & JGJ138-2016 \\
\hline \multicolumn{3}{|c|}{ Structural steel } \\
\hline $\begin{array}{l}\text { Nominal } \\
\text { yield } \\
\text { strength }\end{array}$ & $\begin{array}{c}\mathrm{f}_{\mathrm{y}}: 235 \text { to } 460 \\
\mathrm{~N} / \mathrm{mm}^{2}\end{array}$ & $\begin{array}{c}\mathrm{f}_{\mathrm{ak}}=\mathrm{f}_{\mathrm{ay}}: 235 \text { to } 420 \\
\mathrm{~N} / \mathrm{mm}^{2}\end{array}$ \\
\hline $\begin{array}{c}\text { Steel } \\
\text { grades }\end{array}$ & $\begin{array}{l}\text { S235, S275, S355, } \\
\text { S420, S450, S460 }\end{array}$ & Q235, Q345, Q390 Q420 \\
\hline \begin{tabular}{|l|} 
Thickness \\
categories
\end{tabular} & $\begin{array}{c}\leq 40 \mathrm{~mm}, 80 \mathrm{~mm} \\
>80 \mathrm{~mm}\end{array}$ & $\begin{array}{c}\leq 16 \mathrm{~mm}, 35 \mathrm{~mm}, 50 \mathrm{~mm}, \\
\text { and } 100 \mathrm{~mm}\end{array}$ \\
\hline \begin{tabular}{c|} 
Design \\
strength
\end{tabular} & $\begin{array}{c}\mathrm{f}_{\mathrm{yd}}=\mathrm{f}_{\mathrm{y}} / \gamma_{\mathrm{mi}} \\
\gamma_{\mathrm{m} 0}=\gamma_{\mathrm{m} 1}=1.0\end{array}$ & $\begin{array}{c}\mathrm{f}_{\mathrm{a}}=\mathrm{f}_{\mathrm{ay}} / \gamma_{\mathrm{a}} \\
\gamma_{\mathrm{a}} \approx 1.1\end{array}$ \\
\hline $\begin{array}{l}\text { Elastic } \\
\text { modulus }\end{array}$ & $2.1 \times 10^{5} \mathrm{~N} / \mathrm{mm}^{2}$ & $2.06 \times 10^{5} \mathrm{~N} / \mathrm{mm}^{2}$ \\
\hline \multicolumn{3}{|c|}{ Reinforcement } \\
\hline $\begin{array}{l}\text { Nominal } \\
\text { yield } \\
\text { strength }\end{array}$ & $\mathrm{f}_{\mathrm{sk}}=500 \mathrm{~N} / \mathrm{mm}^{2}$ & $\mathrm{f}_{\mathrm{yk}}=300$ to $500 \mathrm{~N} / \mathrm{mm}^{2}$ \\
\hline \begin{tabular}{|c|} 
Reinforce \\
ment \\
grades
\end{tabular} & $\begin{array}{l}\text { B500A, B500B, } \\
\text { B500C }\end{array}$ & $\begin{array}{c}\text { HPB300 (only for stirrups) } \\
\text { HRB335, HRB400, } \\
\text { HRB500 }\end{array}$ \\
\hline $\begin{array}{l}\text { Design } \\
\text { strength }\end{array}$ & $\begin{aligned} \mathrm{f}_{\mathrm{sd}} & =\mathrm{f}_{\mathrm{sk}} / \gamma_{\mathrm{s}} \\
\gamma_{\mathrm{s}} & =1.15\end{aligned}$ & $\begin{array}{c}\mathrm{f}_{\mathrm{y}}=\mathrm{f}_{\mathrm{yk}} / \gamma_{\mathrm{s}} \\
\gamma_{\mathrm{s}} \approx 1.1\end{array}$ \\
\hline \begin{tabular}{|c|} 
Elastic \\
modulus
\end{tabular} & $2.1 \times 10^{5} \mathrm{~N} / \mathrm{mm}^{2}$ & $\begin{array}{ll}\text { HPB300: } & 2.1 \times 10^{5} \mathrm{~N} / \mathrm{mm}^{2} \\
\text { Others: } & 2.0 \times 10^{5} \mathrm{~N} / \mathrm{mm}^{2}\end{array}$ \\
\hline
\end{tabular}

\section{Limitation of steel-plate slenderness without local buckling checking.}

Local buckling is negligible if the steel plate slenderness does not exceed the limitations listed in Table 3. Two codes give different limitation values for concrete filled tubes based on similar type of formula. Partially encased composite sections are not in the design scope of JGJ138. For fully encased columns, EC4 allows to neglect the local bucking when a minimum value of concrete encasement is provided [5], however, additional checking is still required for the JGJ138 with even much thicker concrete cover.

Table 3.Limitation of steel plate slenderness without checking local buckling

\begin{tabular}{|c|c|c|c|c|}
\hline Туре & EN1994-1-1 & \multicolumn{3}{|c|}{ JGJ138-2016 } \\
\hline & $\frac{\mathrm{d}}{\mathrm{t}} \leq 90 \cdot \frac{235}{\mathrm{f}_{\mathrm{y}}}$ & \multicolumn{3}{|c|}{$\frac{\mathrm{d}}{\mathrm{t}} \leq 135 \cdot \frac{235}{\mathrm{fak}_{\mathrm{ak}}}$} \\
\hline h & $\frac{\mathrm{h}}{\mathrm{t}} \leq 52 \sqrt{\frac{235}{\mathrm{f}_{\mathrm{y}}}}$ & \multicolumn{3}{|c|}{$\frac{\mathrm{h}}{\mathrm{t}} \leq 60 \sqrt{\frac{235}{\mathrm{f}_{\mathrm{ak}}}}$} \\
\hline & $\frac{\mathrm{b}}{\mathrm{t}_{\mathrm{f}}} \leq 44 \sqrt{\frac{235}{\mathrm{f}_{\mathrm{y}}}}$ & & & \\
\hline \multirow{5}{*}{$\stackrel{t}{0}$} & \multirow{5}{*}{$\begin{array}{l}\text { concrete cover to } \\
\text { a flange be no } \\
\text { less than } 40 \mathrm{~mm} \\
\text { nor } 1 / 6 \text { breadth } \\
\text { of the flange }\end{array}$} & $\mathrm{b}_{\mathrm{f} 1} / \mathrm{t}_{\mathrm{f}}$ & $\mathrm{h}_{\mathrm{w}} / \mathrm{t}_{\mathrm{w}}$ & $\mathrm{B} / \mathrm{t}$ \\
\hline & & $\leq 23$ & $\leq 96$ & $\leq 72$ \\
\hline & & $\leq 19$ & $\leq 81$ & $\leq 61$ \\
\hline & & $\leq 18$ & $\leq 75$ & $\leq 56$ \\
\hline & & $\leq 17$ & $\leq 71$ & $\leq 54$ \\
\hline
\end{tabular}

\section{Comparison of design buckling resistance}

For columns only under axial compression and fulfill the requirements listed in Fig. 2, EC4 allows using the simplified method based on European buckling curves to calculate the design buckling resistance $\left(N_{R d}\right)$ as follow (if not consider confinement for circular tubes):

$$
\begin{aligned}
\mathrm{N}_{\mathrm{Ed}} & \leq \mathrm{N}_{\mathrm{Rd}}=\chi \mathrm{N}_{\mathrm{pl}, \mathrm{Rd}} \\
\mathrm{N}_{\mathrm{pl}, \mathrm{Rd}} & =\mathrm{A}_{\mathrm{a}} \mathrm{f}_{\mathrm{yd}}+0.85 \mathrm{~A}_{\mathrm{c}} \mathrm{f}_{\mathrm{cd}}+\mathrm{A}_{\mathrm{s}} \mathrm{f}_{\mathrm{sd}} \\
\chi & =\frac{1}{\phi+\sqrt{\phi^{2}-\bar{\lambda}^{2}}} \leq 1.0 \\
\phi & \left.=0.5\left[1+\alpha(\bar{\lambda}-0.2)+\bar{\lambda}^{2}\right)\right] \\
\bar{\lambda} & =\sqrt{\mathrm{N}_{\mathrm{pl}, \mathrm{Rk}} / \mathrm{N}_{\mathrm{cr}}} \\
\mathrm{N}_{\mathrm{pl}, \mathrm{Rk}} & =\mathrm{A}_{\mathrm{a}} \mathrm{f}_{\mathrm{y}}+0.85 \mathrm{~A}_{\mathrm{c}} \mathrm{f}_{\mathrm{ck}}+\mathrm{A}_{\mathrm{s}} \mathrm{f}_{\mathrm{sk}} \\
\mathrm{N}_{\mathrm{cr}} & =\pi^{2}(\mathrm{EI})_{\mathrm{eff}} / 1_{0}^{2} \\
(\mathrm{EI})_{\mathrm{eff}} & =\mathrm{E}_{\mathrm{a}} \mathrm{I}_{\mathrm{a}}+\mathrm{E}_{\mathrm{s}} \mathrm{I}_{\mathrm{s}}+\mathrm{K}_{\mathrm{e}} \mathrm{E}_{\mathrm{cm}} \mathrm{I}_{\mathrm{c}} \\
\mathrm{E}_{\mathrm{c}, \mathrm{eff}} & =\frac{\mathrm{E}_{\mathrm{cm}}}{1+\left(\mathrm{N}_{\mathrm{G}, \mathrm{Ed}} / \mathrm{N}_{\mathrm{Ed}}\right) \varphi_{\mathrm{t}}}
\end{aligned}
$$


The buckling curves are referenced to EN1993$1-1$, combined with the relative slenderness $\bar{\lambda}$ calculated considering long-term effects and equivalent stiffness of cross-section (EI) $)_{\text {eff }}$ by EC4. For concrete filled tubes, " 0.85 " in Eq. (2) and Eq. (6) can be replaced by 1.0 and for circular tubes concrete confinement should be included. Considering long-term effects $E_{c m}$ in Eq. (8) should be replaced by $E_{c, \text { eff }}$. Imperfection factor $\alpha$ in Eq. (4) (from EN1993-1-1), is 0.21 for buckling curve a, 0.34 for curve $b$ and 0.49 for curve c. The reduction factor $K_{e}$ is 0.6 .

For JGJ138, the buckling curve ( $\varphi$ to $l_{0} / i$ in Table 5) borrowed from GB50010 [4], is used for both fully encased columns and concrete filled rectangular columns. Imperfection and long-term effects are already included in the buckling reduction factor $\varphi$ [7]. The reduction factor " 0.9 " in Eq. (10) to (12) is the parameter related to the reliability of column.

For fully encased composite section:

$$
\mathrm{N} \leq 0.9 \varphi\left(\mathrm{f}_{\mathrm{c}} \mathrm{A}_{\mathrm{c}}+\mathrm{f}_{\mathrm{y}}^{\prime} \mathrm{A}_{\mathrm{s}}^{\prime}+\mathrm{f}_{\mathrm{a}}^{\prime} \mathrm{A}_{\mathrm{a}}^{\prime}\right)
$$

For concrete filled rectangular tube:

$$
\mathrm{N} \leq 0.9 \varphi\left(\alpha_{1} \mathrm{f}_{\mathrm{c}} \mathrm{A}_{\mathrm{c}}+\mathrm{f}_{\mathrm{a}} \mathrm{A}_{\mathrm{a}}\right)
$$

For concrete filled circular tube:

$$
\begin{aligned}
& \mathrm{N} \leq\left\{\begin{array}{lll}
0.9 \varphi_{\mathrm{l}} \mathrm{f}_{\mathrm{c}} \mathrm{A}_{\mathrm{c}}(1+\alpha \theta) & ; & \theta \leq[\theta] \\
0.9 \varphi_{\mathrm{l}} \mathrm{f}_{\mathrm{c}} \mathrm{A}_{\mathrm{c}}(1+\sqrt{\theta}+\theta) & ; & \theta>[\theta]
\end{array}\right. \\
& \theta=\mathrm{f}_{\mathrm{a}} \mathrm{A}_{\mathrm{a}} / \mathrm{f}_{\mathrm{c}} \mathrm{A}_{\mathrm{c}} \\
& \varphi_{\mathrm{l}}=\left\{\begin{array}{ccc}
1-0.115 \sqrt{\mathrm{L}_{\mathrm{e}} / \mathrm{D}-4} & ; & \mathrm{L}_{\mathrm{e}} / \mathrm{D}>4 \\
1 & ; & \mathrm{L}_{\mathrm{e}} / \mathrm{D} \leq 4
\end{array}\right.
\end{aligned}
$$

Where:

$A_{a}\left(A_{a}^{\prime}\right), A_{c}$, is cross-section areas of steel, concrete, and $\mathrm{A}_{\mathrm{s}}\left(\mathrm{A}_{\mathrm{s}}^{\prime}\right) \quad$ reinforcement respectively.

$f_{y d} ; f_{a}\left(f_{a}^{\prime}\right)$ is design strength of profiled steel.

$f_{c d} ; f_{c} \quad$ is design compression strength of concrete.

$f_{s d} ; f_{y}^{\prime}$ is design compression strength of reinforcement.

$f_{y k}, f_{c k}, f_{s k} ;$ is characteristic strength value of steel,

concrete, and reinforcement respectively.

$E_{c m} \quad$ is the mean elastic modulus of concrete.

$I_{a}, I_{C}, I_{S} \quad$ is moment of inertia of each part respectively.

$N_{E d}, N_{G, E d}$ is design compressional force and the part of permanent loads.

$\varphi_{t} \quad$ is creep coefficient of concrete at time $\mathrm{t}$

$\alpha, \alpha_{1}, \theta \quad$ parameters related to concrete-Table 4 .

$l_{0}, L_{e} \quad$ is the calculation length of the column.

$\varphi \quad$ is buckling reduction factor-Table 5 .

Table 4.Values of $\alpha, \alpha_{1}, \theta$ in JGJ138

\begin{tabular}{|c|c|c|c|}
\hline Concrete class & $\leq \mathbf{C 5 0}$ & C55 to C75 & C80 \\
\hline$\alpha$ & 2.0 & 1.8 & 1.8 \\
\hline$\alpha 1$ & 1.0 & interpolation & 0.94 \\
\hline$[\theta]$ & 1.0 & 1.56 & 1.56 \\
\hline
\end{tabular}

Table 5. Values of $\varphi$ for flexure buckling for JGJ138

\begin{tabular}{|c|c|c|c|c|c|c|}
\hline$l_{0} / i$ & $\leq 28$ & 35 & 42 & 48 & 55 & $\mathbf{6 2}$ \\
\hline$\varphi$ & 1.0 & 0.98 & 0.95 & 0.92 & 0.87 & 0.81 \\
\hline$l_{0} / i$ & 69 & 76 & $\mathbf{8 3}$ & 90 & 97 & 104 \\
\hline$\varphi$ & 0.75 & 0.70 & 0.65 & 0.60 & 0.56 & 0.52 \\
\hline \multicolumn{2}{|c|}{ Note: $\mathrm{i}=\sqrt{\left(\mathrm{E}_{\mathrm{c}} \mathrm{I}_{\mathrm{c}}+\mathrm{E}_{\mathrm{a}} \mathrm{I}_{\mathrm{a}}\right) /\left(\mathrm{E}_{\mathrm{c}} \mathrm{A}_{\mathrm{c}}+\mathrm{E}_{\mathrm{a}} \mathrm{A}_{\mathrm{a}}\right)}$} & & $(15)$ \\
\hline
\end{tabular}

\subsection{Comparison based on parameter studies}

The buckling resistance $\left(N_{R d}\right)$ according to the simplified method based on the European buckling curves in EC4 is compared with axial compression resistance according to JGJ138. In addition, the influence of long-term effects on flexure stiffness and comparison of buckling curves are investigated.

Fully encased composite sections of different calculation height are calculated. The design information and the buckling resistances of both axes are shown in Fig. 4. For JGJ138, the smaller material strength values and the reduction factor 0.9 in Eq. (10) result in smaller buckling resistance value for compact columns compared to EC4. However, for slender columns, JGJ138 gives bigger buckling resistance. EC4 uses two different types of buckling curves (yy: curve-b, zz: curve-c), thus, the resistance in major and minor axes have big differences. JGJ138 uses same buckling curve, which gives similar resistance.

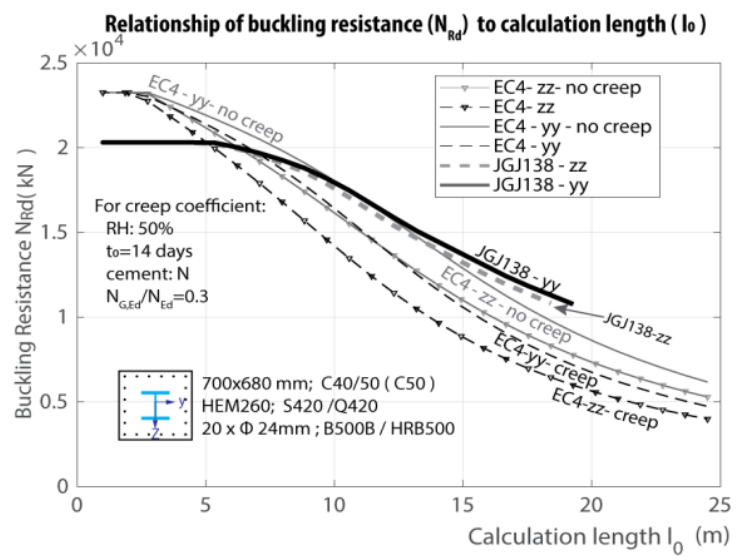

Fig. 4. Buckling resistance to calculation length of full-encased composite section

EC4 considers long-term effects of concrete by using a reduced effective elastic modulus of concrete $\mathrm{E}_{\mathrm{c}, \mathrm{eff}}$ (Eq.(9)) which increases the relative slenderness $\bar{\lambda}$. To investigate the influence, two attentional curves with concrete creep coefficient equal to zero $\left(\varphi_{t}=0\right)$ are added in Fig. 4. Comparison shows the longterm effects can reduce buckling resistance up to $25 \%$. (Fig. 4) 
Concrete filled rectangular tubes, with different height/breadth ratios $(\mathrm{h} / \mathrm{b}=1,1.3,1.6$, 1.9) but same plastic compression resistance are investigated. Because only minimum required reinforcement ratio is considered, rebars are not included in the calculation. Buckling curve "a" is used according to EC4. The creep coefficient used here for EC4 is 0.25 times of the calculated $\varphi_{t}$ value by neglecting the steel tube, based on the German National Annexe [5, 8].

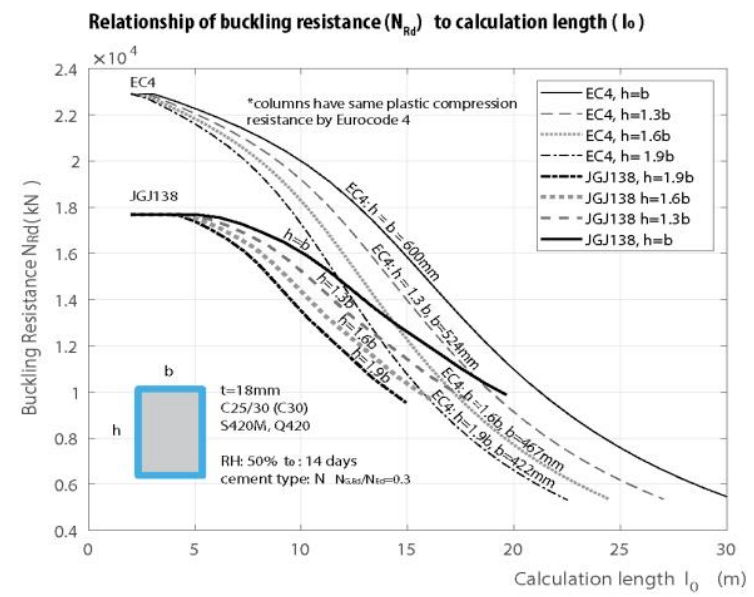

Fig. 5. Buckling resistance to calculation length of concrete filled rectangular tubes

With increasing $\mathrm{h} / \mathrm{b}$ ratios, the slenderness of $\mathrm{z}$ axis gets bigger. Thus the buckling resistance controlled by the z-axis decreases. In EC4, because of using 1.0 instead of 0.85 in Eq. (2), concrete plastic compression resistance further raises. The differences of buckling resistance of compact columns are greatly increased. Overall, JGJ138 shows conservative design buckling strength compared to EC4 (Fig. 5).

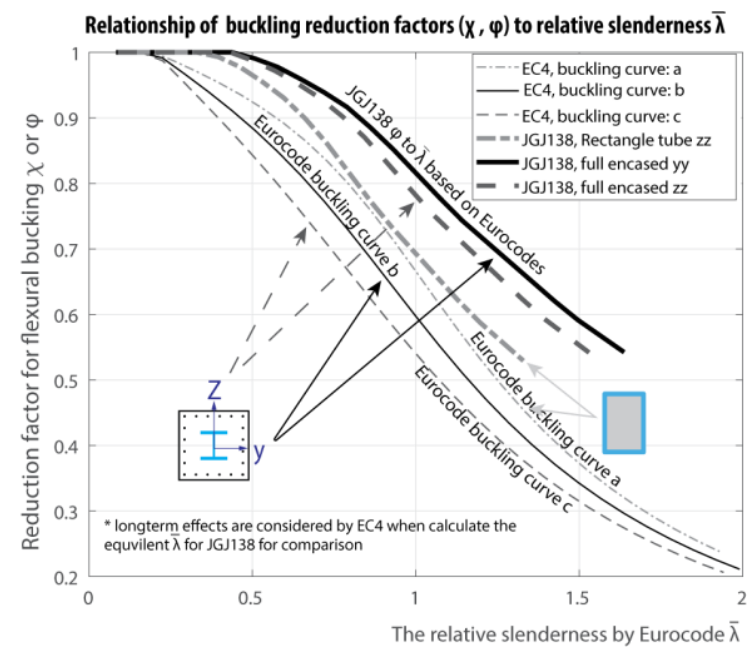

Fig. 6. Comparison of buckling curves
For both fully encased composite sections and concrete filled rectangular tubes, JGJ138 uses the same buckling curve defined as the bulking reduction factor $\varphi$ based on $l_{0} / i$ (Eq. (15)). Eurocode 4 on the other hand, uses the buckling curves based on reduction factor $\chi$ to the relative slenderness $\bar{\lambda}$. To make them comparable, the JGJ138 $l_{0} / i$ is transferred to the EC4 $\bar{\lambda}$. The $\varphi-$ $\bar{\lambda}$ curves are not constant for individual crosssections depending on geometry and material. The curves for the before mentioned columns are shown in Fig. 6. All the three buckling curves according to JGJ138 has bigger value of buckling reduction factors than EC4.

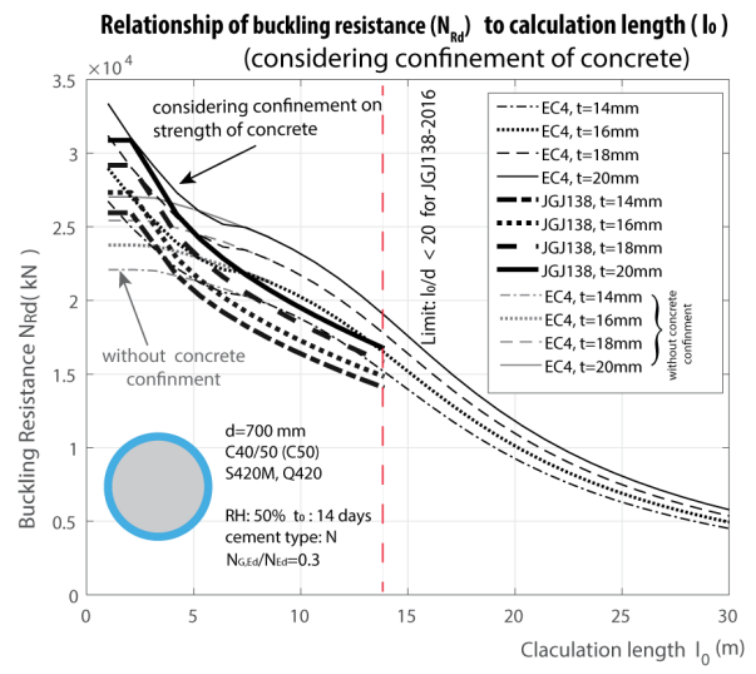

Fig. 7. Buckling resistance to calculation length of concrete filled circular tubes

The design buckling resistances of concrete filled circular tubes are shown in Fig. 7. Columns with different steel tube thickness are investigated with (or without) consideration of concrete confinement. The creep coefficient used for EC4 is $0.25 \varphi_{t}[5,6]$ For JGJ138 the column calculation length is suggested to be no more than 20 times of the diameter of crosssection. In general, design buckling resistances according to Eurocode 4 are higher than in JGJ138 for most situations, but the difference is reduced compared to the case of concrete filled rectangular columns.

\section{Comparison of $\mathrm{N}-\mathrm{M}$ interaction curves}

The N-M interaction curves in Eurocode 4 is represented by simplified four points polygonal diagram. For JGJ138 the N-M interaction curves are not directly given but can be made using the formulas of eccentric compression resistance. 
JGJ138 gives three different sets of equations for each type of composite columns. The fully encased columns and concrete filled rectangular tubes have a similar mechanic model (identical to EC4) based on cross-section resistance. For concrete filled circular tubes, the design mythology is different from the rest.

\subsection{Design methods of $N$-M interaction}

The N-M interaction curve according to Eurocode 4 is based on the rectangular stress blocks with stress value of plastic strength [9] (Fig. 8.a). The influence of transverse shear is considered by a reduced design steel strength $(1-\rho) f_{y d}$ in the shear area, if the shear force exceeds half of the design shear resistance. In practice, a simplified polygonal diagram with 4 points is used instead of the exact plastic curve. To take into account of the difference between the full plastic and the elastoplastic resistance of the cross-section, resulting from the strain limitations for concrete as well as other effects, a reduction factor $\alpha_{M}$ on design moment resistance is used. ( $\alpha_{M}=0.8$ for S420 and S460 and 0.9 for S235 and S355). The design bending moment should fulfil condition: $M_{E d} \leq M_{R d}=$ $\alpha_{M} \mu M_{p l, R d}$,where $\mu$ is the reduction factor due to the normal force, which can be calculated based on N-M interaction curve.

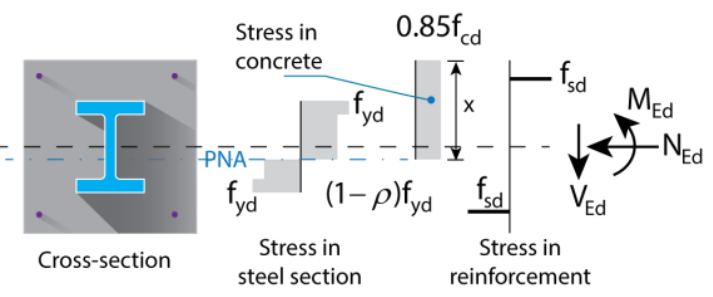

a) Stress distribuation according to EN1994-1-1

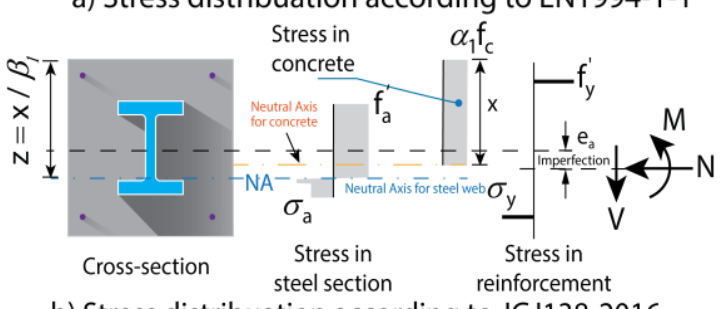

b) Stress distribuation according to JGJ138-2016

Fig. 8. Mechanic models for N-M interaction curves

Design of fully encased composite sections and concrete filled rectangular tube by JGJ138 also use rectangular stress blocks, but with different plastic neutral axes for steel and concrete (Fig. 8.b). For the steel flanges and the reinforcements in tensile or smaller compressive side, the stresses $\left(\sigma_{a}, \sigma_{y}\right)$ should be calculated based on the location of neutral axis. The influence of transverse shear on strength of steel is not considered. Additional geometrical eccentric of the axial loads $\left(e_{a}\right)$ is added to represent impact of imperfection, and to align the maximum design compression strength with the result from axial buckling resistance. For concrete filled rectangular tube, on condition of small eccentric compression, the stresses in steel plates along cross-section height direction are represented by stress blocks with different stress value below and above the neutral axis. The stress in compression part is assumed to be design strength $f_{a}$, while the tensile parts is the stress value of steel plate at lower surface $\sigma_{a}$, contribution of reinforcement is neglected.

For the concrete filled circular tubes, JGJ138 uses empirical formula, which considers buckling, concrete confinement, imperfection and other factors. Reinforcement is only required when the diameter of column exceeds $2000 \mathrm{~mm}$ and is not considered by resistance calculation.

\subsection{Parameter studies of $N-M$ interaction curves}

Fully encased composite sections with different concrete or steel grades are compared. (Fig. 9, Fig. 10). Although both codes are based on the cross-section resistance, Eurocode 4 has higher plastic compression resistance resulting mainly from higher material strength values. The maximum bending moment resistance $M_{R d}$ of EC4 with steel grade S420, S460 $\left(\alpha_{M}=0.8\right)$ is smaller than by JGJ138. But when S235 to S355 is used $\left(\alpha_{M}=0.9\right)$ the maximum $M_{R d}$ can be greater than the values from JGJ138.

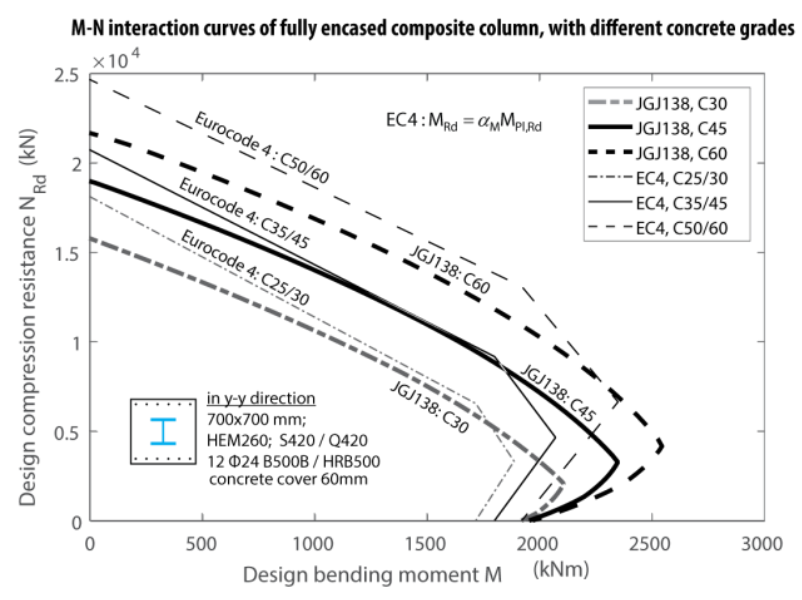

Fig. 9. N-M interaction curves of fully encased composite column (with different concrete grades) 


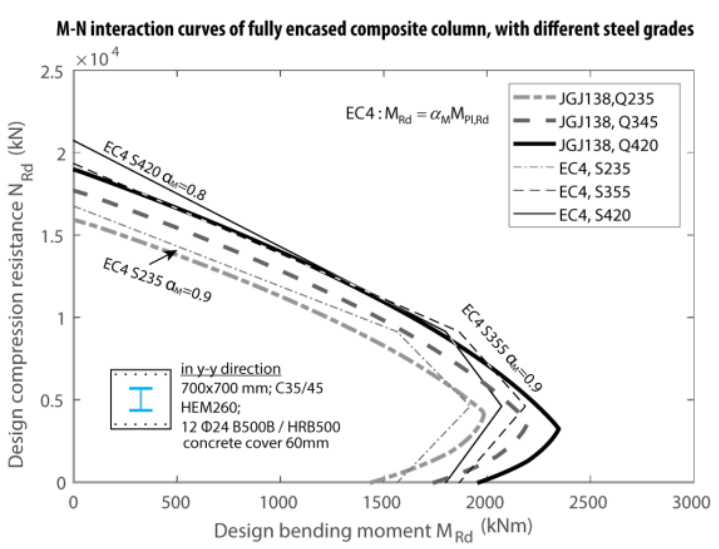

Fig. 10. N-M interaction curves for fully encased column (with different steel grades)

Concrete filled rectangular tubes with changing height to breadth ratios $(\mathrm{h} / \mathrm{b}=1.0,1.3$, $1.6,1.9)$ but same plastic compression resistance are compared (Fig.11). Similar to the fully encased composite sections, when $\alpha_{M}$ equal to 0.8 the maximum design bending moment $M_{R d}$ by EC4 is smaller (Fig.11.a). When $\alpha_{M}=0.9 \mathrm{~N}$ $\mathrm{M}$ interaction curves according to EC4 is outside of the relevant curve by JGJ138.
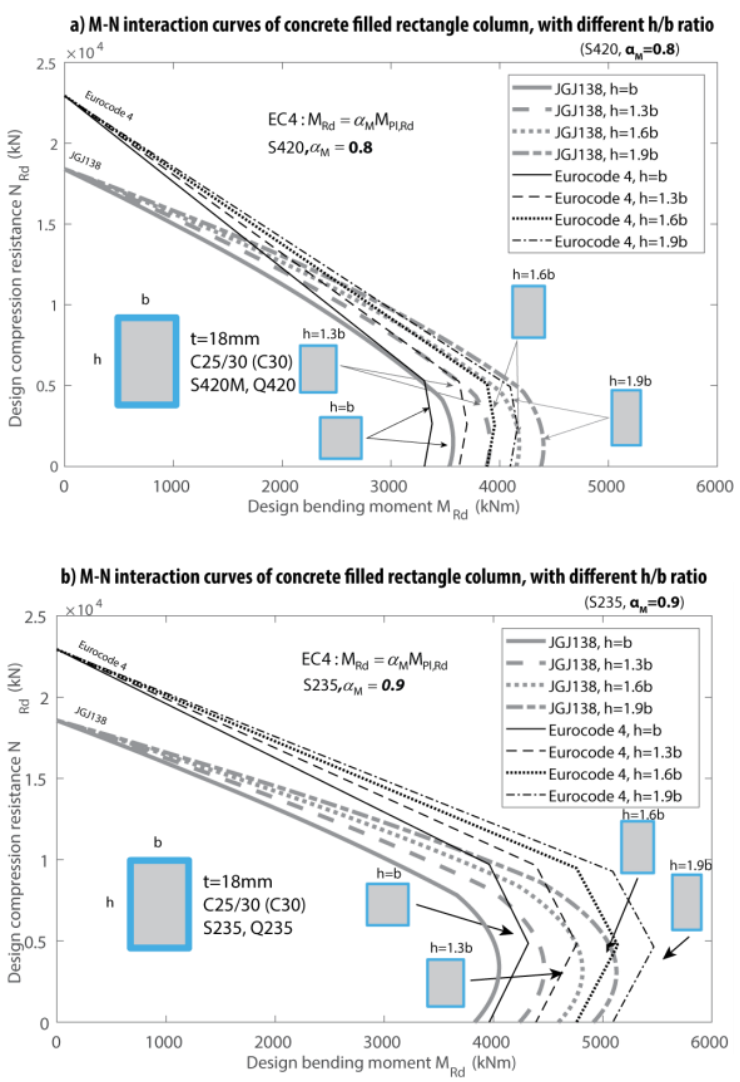

Fig. 11. N-M interaction curves of concrete filled rectangular tubes

For the concrete filled circular tube, the N-M curves are not comparable for the following reasons: For JGJ138, the N-M curves are not only based on the cross-section resistance, factors like concrete confinement, buckling of the column are also considered. Thus with changed column length or supports condition, different N-M curves can be generated (Fig.12). For EC4, on the other hand, the N-M curve only represents the cross-section resistance.

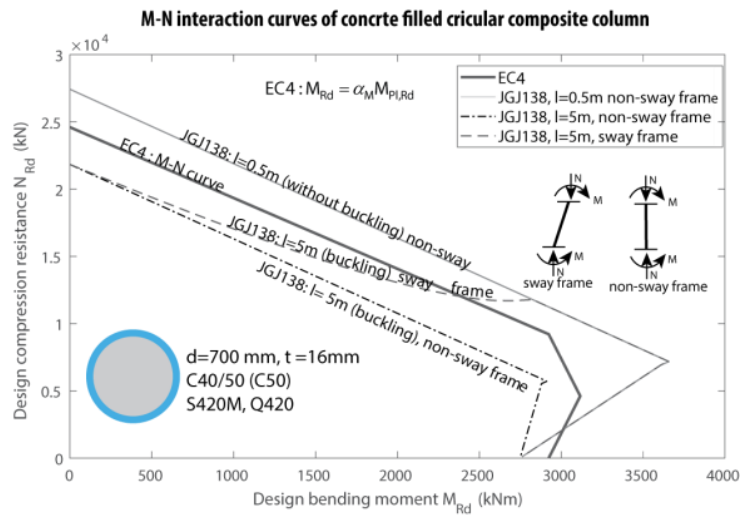

Fig. 12. N-M interaction curves of concrete filled circular tubes

\section{Comparison of shear resistance}

Eurocode 4 considers mainly the following aspects of influence of shear: First influence of transverse shear forces on the bending and normal force resistance should be considered (§ 6.1). Second, the transversal shear resistance should be verified separately for steel and concrete parts. Third, the longitudinal shear resistance, i.e. the force transfer between concrete and steel sections needs also to be checked.

For JGJ138-2016, only the checking for transversal shear resistance is required. For different types of columns, different formulas are given. The comparison of transversal shear resistance is shown below:

\section{EN1994-1-1:}

$$
\begin{aligned}
& \text { Steel: } V_{a, E d}=V_{E d} \cdot \frac{M_{a}}{M_{R d}} \approx \frac{M_{p l a, R d}}{M_{p l, R d}}<V_{p l a, R d} \\
& \text { Concrete: } V_{c, E d}=V_{E d}-V_{a, E d}<V_{c, R d}
\end{aligned}
$$

Where:

$V_{a, E d}, V_{c, E d}, V_{E_{d}}:$ Design transverse shear force of steel, concrete and composite section.

$V_{\text {pla,Rd }}: \quad$ Design transverse shear resistance of steel

$V_{c, R d}$ : $\quad \begin{aligned} & \text { Section. (Calculated based on Eurocode 3) } \\ & \text { Design transverse shear resistance of }\end{aligned}$ concrete section. (Calculated based on Eurocode 2)

$M_{p l a, R d}, M_{p l, R d}:$ Plastic moment resistance of steel section, composite section respectively. 


\section{JGJ138-2016 (for eccentric compression):}

Fully encased composite section (frame column):

$$
\begin{gathered}
V_{c} \leq \frac{1.75}{\lambda+1} f_{t} b h_{0}+f_{y v} \cdot \frac{A_{s v}}{s} h_{0}+\frac{0.58}{\lambda} f_{a} t_{w} h_{w}+0.07 N \\
V_{c} \leq 0.45 \beta f_{c} b h_{0} \quad f_{a} t_{w} h_{w} / \beta f_{c} b h_{0} \geq 0.1
\end{gathered}
$$

Concrete filled rectangular tube:

$$
V_{c} \leq \frac{1.75}{\lambda+1} f_{t} b_{c} h_{c}+\frac{1.16}{\lambda} f_{a} t h+0.07 N
$$

Concrete filled circular tube $(\mathrm{a}=\mathrm{M} / \mathrm{V}<2 \mathrm{D})$ :

$$
V \leq\left[0.2 f_{c} A_{c}(1+3 \theta)+0.1 N\right](1-0.45 \sqrt{a / D})
$$

Where:

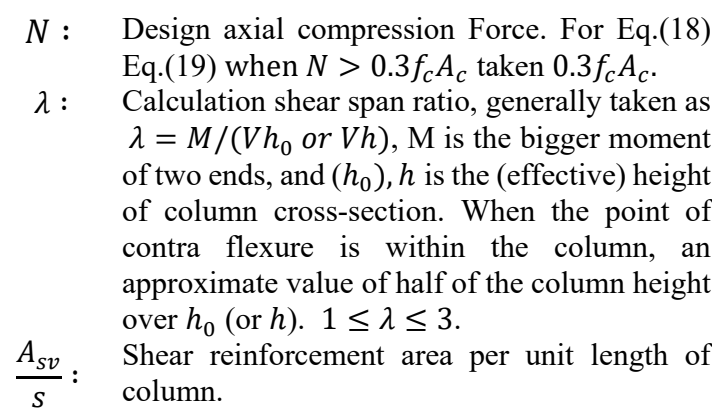

\section{Conclusions}

The design scopes of the JGJ138-2016 and simplified method in Eurocode 4 are different: JGJ138 contains design guides separately for fully encased composite sections, concrete filled rectangular and circular tubes. EC4 simplified method covers more types of sections and gives unified design procedures. JGJ138 is suitable for the design of large cross-sections; the EC4 simplified methods are also applicable for small size columns. Also, the general method based on the non-linear analysis in Eurocode 4 allows the design of irregular composite columns.

Eurocode 4 allows using up to C50/C60 concrete, JGJ138 can use up to C80. However, the Chinese $\mathrm{C} 80$ has similar strength values to the European C50/60. For structural steel, the material partial safety factors of JGJ138 is higher than EC4 recommended value, which gives a general smaller design strength value. EC4 allows using higher grades structural steel; JGJ138 allows the lower strength reinforcement.

For buckling resistance: JGJ138 has smaller buckling resistances for compact columns due to the lower material strength values used in the design. However, the resistance for slender columns can be bigger than EC4. Long-term effects can reduce the buckling resistance up to around $25 \%$ by EC4. JGJ138 considers it through the buckling curve for fully encased composite section or concrete filled rectangular tube without detailed calculation.

Pure compression resistance by $\mathrm{N}-\mathrm{M}$ interaction curves according to EC 4, is higher than JGJ138, mainly due to the material strength differences. The reduction factor $\alpha_{M}$ included in the plastic moment resistance for EC4 has a big impact on the design bending moment. If $\alpha_{M}=$ 0.8 the maximum design bending moment is usually smaller than according JGJ138, when $\alpha_{M}=0.9$, EC4 get on the other hand, usually bigger value.

For the concrete filled circular tube, both codes consider the confinement effects of concrete for axial buckling resistance. But the N$\mathrm{M}$ interaction curves are not comparable as different design method basis are used.

EC4 and JGJ138 both provide the design methods for transverse shear. Furthermore, Eurocode 4 considers the influence of transverse shear on bending moment resistance and load transfer between concrete and steel.

\section{References}

[1] Zhang Q, Schäfer M. Comparison of design for composite beams in steel and concrete according to Eurocode 4 and Chinese Design Codes. XI Conference on Steel and Composite Construction; Wiley Online 2017.

[2] JGJ138-2016. 组合结构设计规范 [S], Code for design of composite structures 2016.

[3] Eurocode 4. Design of composite steel and concrete structures, Part 1-1. EN1994-1-1, General rules for buildings 1994.

[4] GB50010-2010. 混凝土结构设计规范 [S], Codes for design of concrete structures 2010.

[5] Hanswille G, Schäfer M, Bergmann M. Kommentar zur EN 1994-1-1, Design Guide to EN 1994-1-1. Stahlbaukalender 2018.

[6] Schäfer M, Banfi M. Background Report to EN 1994-1-1, CEN/TC 250/SC 4 N 1814; Luxemburg/London 2017.

[7] Chen W, Kang G, and Yan D. 混凝土结构 (上册) 2002: 128-129.

[8] DIN EN 1994-1-1/NA: 2010-12. National Annex - Eurocode 4; EN 1994-1-1, Design of composite steel and concrete structures.

[9] Roik K, Bergmann R. Harmonisation of the European Construction codes - Report of Eurocode; 1989 